\title{
The mathematics teacher's profession: the perspective of future
}

\author{
Ana Rosa Corica, María Rita Otero \\ Consejo Nacional de Investigaciones Científicas y Técnicas (CONICET), Núcleo de Investigación en Educación en Ciencia y \\ Tecnología (NIECyT), Facultad de Ciencias Exactas de la Universidad Nacional del Centro de la Provincia de Buenos Aires, \\ Tandil, Argentina \\ For correspondence: acorica@exa.unicen.edu.ar
}

\begin{abstract}
:
We present partial results of the design and implementation of a study program for the Mathematics Teacher Training. The research is developed in the light of the Anthropological Theory of the Didactic. This paper we analyze what gestures of the research and world questioning pedagogy are identified in a group of future teachers that study an essential issue to the mathematics teacher profession: how to teach mathematical knowledge? The work was carried out with futures mathematics teachers of the third year of a careen university in Argentina. The main results indicate that the future teachers, at the beginning of the study program, do not seem to carry out the distinctive didactics gestures of the research and questioning the world pedagogy.
\end{abstract}

Keywords: Teacher training, Anthropological Theory of the Didactic, Research and Study Path, Mathematics

\section{Introduction}

The research is on the issue of the mathematics teachers' training. Several researchers have addressed this issue from different theoretical perspectives whose efforts are directed to provide information to help making decisions about the teacher training (Artaud, Cirade \& Jullien, 2011; Azcárate, 2004; Blanco, 2004; Bosch \& Gascón, 2009; Chapman, 2013; Corral \& Zurbano, 2000; Font, 2011; García, 2001; Gascón, 2003; Koc, Peker \& Osmanoglu, 2009; Parada \& Pluvinage, 2014; Polo, González, Gómez \& Restrepo, 2011; Rico, 2004; Robert \& Pouyanne, 2005; Ruiz \& Sierra, 2011; Sanchez, 2003; Sanchez \& García, 2004; Sierra, Bosch \& Gascón, 2012; Silverman \& Thompson, 2008; Steff \& Thompson, 2000; Towers \& Rapke, 2011). particularly, several investigations aimed at identifying the knowledge that a teacher should have to develop effective practices (Ball, Lubienski \& Mewborn, 2001; Font, Rubio, Giménez \& Planas, 2009; Godino, 2009; Hill, Ball \& Schilling, 2008; Hill, Schilling \& Ball, 2004; Rubio, Font, Giménez \& Malaspina, 2011; Sowder, 2007; Wood, 2008).

On the order hand, Bosch \& Gascón (2009) consider that the issue of teacher training is not solved with the necessary skills for the practice of the teaching profession. Since it does not report how to determine the process and the conditions to acquire or develop specific skills.

In another investigation with future teachers of mathematics, whose training focuses on the acquisition of a didactic praxeological equipment based on the Anthropological Theory of Didactics, it is reported that future teachers design and manage didactics devices in which they incorporate some gestures on the research and questioning the world pedagogy (Corica \& Otero, 2013, 2014). Thus, in order to enter the research pedagogy it is vital to manage the Study and Research Dialectic (Chevallard, 2013a). This requires to generate permanent encounters through questions formulated in a strong sense. However, during the lessons of the future teachers, the students behaved as in the traditional teaching: answer and no enquire. Holding in time the enquire and not put ahead the answers is a process that declines with time. This leads to future teachers going back to the monumental teaching. Therefore, they experience the study process as the universal medium, which Chevallard called teacher pedagogy (Marietti, 2010): the insertion of the study notions is monitored by the teacher. The students 
are invited to visit these knowledge modules as we visit a monument. Their places are reduced to admire and venerate these monuments.

Our results show that the theoretical training does not guarantee that future teachers acquire a didactic praxeological equipment. In this paper we present partial results of the design and implementation of a study program for future teachers in Mathematics. The principal aim is that these future teachers adopt a non-traditional pedagogy model, based on research and on linking mathematics with other disciplines. In particular, we analyze which elements of the research pedagogy are identified in a group of future teachers that study the essential issue to the mathematics teacher profession, which is how to teach mathematical knowledge?

\section{Theoretical framework}

In this work we adopt as theoretical framework the Anthropological Theory of the Didactic (Chevallard, 1999, 2007, 2013a, 2013b; Ladage \& Chevallard, 2010, Otero et. al, 2013). Following the lines suggested in the theory, there is a need to introduce into education systems functional study processes in which the knowledge does not constitute monuments that the teacher teaches to the students, but material and conceptual tools, useful to study and to solve problematic situations. The Study and Research Path (SRP) are devices that would allow facing the monumentalization process of knowing knowledge and giving life to what Chevallard calls research pedagogy in the math class (Ladage \& Chevallard, 2010). To establish this pedagogy is required to install a set of didactics gestures, which involve radical changes to the traditional teaching (Chevallard, 2013a). These didactics gestures which are interrelated are:

Problematization attitude. It consists in recognizing the problematic situations lived or observed and in preparing to formulate new questions.

Herbartian attitude. It consists in not avoiding the questions, but in submitting to its study, as well as not to avoid to the mathematics.

Procognitiva attitude. It is always known to the future, expanding the field of interest, but though beforehand, we do not know much about the object of study.

Exoteric attitude. It is to accept that the knowledge is gained. The exoteric attitude is articulated with two principles related to knowledge and ignorance: 1) we are allowed not to know, and this in every domain; 2) we have to deal with its ignorance to progress as much as possible and useful towards a suitable knowledge for the project that this knowledge is considered to serve.

Regular encyclopedic attitude. It Consists in looking at oneself as no oblivious to the set of possible praxeological fields, even though this is for a large number of them, with a degree of exotericidad next to zero, constantly striving to grow as much as useful, this degree of exotericidad .

The SRP pedagogy questions the elements of the traditional school contract: the teacher as the temple of knowledge as the sole guarantor of the validity of the answers, as manager of instructional time, and the learning individual nature. These elements are replaced by the model of a collective study process, led by a teacher who shares with the group of students the responsibility of managing the different didactics moments. The objective of the study is defined as a question set $\mathrm{Q}$ which the study community proposes to provide a response $\mathrm{R}$. The starting point of a SRP is a generative question $\mathrm{Q}$ alive for the study community and whose answer is not directly accessible.

This response must constitute itself a significant contribution in the sense of expanding the praxeological universe of the study community. In this model, during study activity, all the resources, means, knowledge and answers available are mobilized to build R. Thus, it will result in generally including praxeologies, at least local, integrating praxeological elements that can go beyond the regional level and even discipline.

Implementing an SRP teaching modifies the relationship between teacher, students and knowledge. This implies changes related to didactics time (chronogenesis), the way that the study is organized 
(mesogenesis) and the place occupied by the didactic system actors in the class (topogenesis). In particular, the management of teaching by SRP requires executing didactic gestures typical of the study and research, called dialectic (Chevallard, 2007, 2013a, 2013b). nowadays, there are 9 dialectical: parashutist and truffles dialectics, entering and departing off topic dialectics, black boxes and clear boxes dialectics, excription textual and textual inscription dialectics, the media and the medium dialectic, disseminating and receiving answers dialectic, individual and collective dialectic, analysis and synthesis praxeological and didactic dialectic, study and research dialectic. In particular, we consider that the Study and Research dialectic is the engine of a teaching by SRP. It is not possible to investigate without studying and a genuine study is producer of questions to being investigated. Therefore, new questions arise for the study community who will decide when and how to answer.

\section{Methodology}

This research is qualitative. The methodology proposed is exploratory and ethnographic (Hernández, Fernández \& Baptista, 2010). Since in this study we attempt to understand how future teachers live part of their didactic training from a study program that we developed in the context of the ATD.

We designed and implemented a study program concerned with notions of mathematics didactic aimed at future teachers in Mathematics (FT). The main objective was that the FT can adopt gestures of a nontraditional pedagogy model, based on research and on linking mathematics with other disciplines.

The proposal raises two situations; in the first, it is proposed to FT to carry out a Study and Research Path on the mathematics teaching; in the second situation, the FT studied a codisciplinar SRP (Parra, Otero \& Fanaro, 2013a, 2013b), designed for high school students, where the study leads to establish links between mathematics and other disciplines.

In the first situation, we intend that the teachers training college students experience by themselves the study of ATD involved in a teaching based on the principles of research pedagogy and world questioning. Here we develop an active in which not foreseen questions arose at the outset, causing that the study o occur in different directions. Approaching with major or minor depth the study of these questions was relegated to the interest of the community. The second situation had as an objective that FT live an codiscipline SRP since all along their academic training they have never been involved in a teaching governed by the research pedagogy and world questioning. When circumstances allowed it, we sought to study both situations in a complementary way.

This paper presents a pedagogical analysis of the first session about the situation regarding the mathematics teaching. This session proved to be vital since we establish the primary means for the study in the following sections. We analyze the study gestures and study aid that took place during the first session, both by students and by the study process director.

\section{Institutional Description about the Course where the research was conducted}

The research took place in a third-year course corresponding to Teacher Training in Mathematics in a National University in Argentina. In particular, the study program proposes to focus on the training of FT in the ATD. In previous courses, the FT studied as didactic training in teaching mathematics: Didactical Situations Theory (Brousseau, 1986), Instrument - Object Dialectic and frame playing (Douady, 1984), Didactic Transposition Theory (Chevallard, 1985) and the fundamental principles of the Anthropological Theory of Didactics (Chevallard, 1999). The course was composed of 12 students, whose ages ranged from 20 to 28 years old.

The course lasted 4 months with two weekly meetings of 4 and 3 hours, respectively. During the 4hour meetings FT participated in the SRP on mathematics teaching in 12 sessions where Research Teacher (RT) was the study director.

During the meetings of 3 hours, the FT experienced as students a codisciplinare SRP. These classes were conducted by the researcher who developed the didactic device. To begin with, a commitment act was signed. The act is composed by a set of working agreements for the course. Basically this act 
contemplates accepting the answers of the entire study community, accepting mistakes as a part of the learning process, taking responsibility for their own learning, committing to produce and disseminate knowledge and agreeing on course evaluation forms.

In All class sessions the FT formed the same workgroup. 5 groups of 2 or 3 members each were formed, which are identified as follows: Groups 1: $F T_{1}^{1}, F T_{2}^{1}$; Groups 2: $F T_{1}^{2}, F T_{2}^{2}, F T_{3}^{2}$; Groups 3: $F T_{1}^{3}$, $F T_{2}^{3}$; Groups 4: $F T_{1}^{4}, F P_{2}^{4}$; Groups 5: $F T_{1}^{5}, F T_{2}^{5}, F T_{3}^{5}$.

\section{Data Collection}

During the implementation of SRP on the mathematics teaching, the RT was a participant observer. He took a general audio of each session and field notes before and during the implementation of each sessions. In the first session, the RT proposed a generating initial question and during the subsequent lessons, when circumstances required, he provided material for study. So questions and answers developed by each group were withdrawn at the end of each session and were scanned and given back to students in the immediate following session. This assures that students do not change their answers after each session, the continuity of their work, and allows them to have their texts permanently. All students' written protocols of students of each implementation were obtained. After each session the FT completed an on-line journal that was shared with all study community. This allowed us to collect the students' experiences made known in writing.

In particular, in the first session in a large group, and as a synthesis of the contributions of the various working groups, the community developed a study package proposal of the means to study throughout the course. This medium was the starting point of the SRP about the teaching of mathematics, consisting of different viewpoints. In the subsequent sessions, the different groups contributed questions pairs $\left(Q_{i}\right)$ and answers $\left(A_{i}\right)$ according to their interests and needs. These proposals had different specific objectives for different workgroups.

\section{Data analysis}

The data analyzed are the product of the protocols that we collected from students and general audio transcription of the first session. For data analysis, the transcription of the general audio was segmented into episodes and its study was supplemented from the study protocols. The criteria adopted for the segmentation in episode was when the community study speech raises a new question. This allowed sorting pairs of questions and answers provided by the study community and identifying the actors who were the producers. Finally, we formulated categories inductively, that permitted to make inferences about the types of questions that constitutes the primary means of study.

\section{Analysis of the SRP implementation about the mathematics teaching}

In the first session we presented a video about different possible classroom situations to provoke FT reflection and place them in understanding and designing teaching practices. The video questions the student activity in the classroom into two prototypical cases of students: one is characterized by having autonomy for the study and by expressing interest in learning to learn; and another student who only takes the course in order to pass it. These two types of students are exemplary and extreme cases that often occur in any class, discipline and education. In the same video, the job of the teacher in relation to their role in the study process is problematized. These situations allow generating a space for reflection focused on determining the fundamental problems that the teacher faces when performing his profession as a teacher.

Then we proposed to FT to work in groups and carry out the following task:

In each working group reflect on the video about teaching and learning. Then discuss the following question:

$Q_{0}:$ How to design and implement didactics devices for the mathematics study? 
You are required to write all the arguments, questions, hypotheses, agreements and disagreements that emerge in the group during the question study.

The study of $Q_{0}$ led to the formulation of questions and answers pairs $\left(Q_{i}, A_{i}\right)$, which we detailed below. We highlight that the RT had to intervene several times so that students are located not only in giving answers. In the face of a question FT show the need of providing an immediate and finished answer, as if there was nothing more to investigate and learn.

In Scheme 1 we summarize the set of questions and answers $\left(Q_{i}, A_{i}\right)$ that emerged from the $Q_{0}$ study. The diagram shows the questions set that formed the study means of the FT for the subsequent sessions. In dotted lines we include questions installed by the RT.

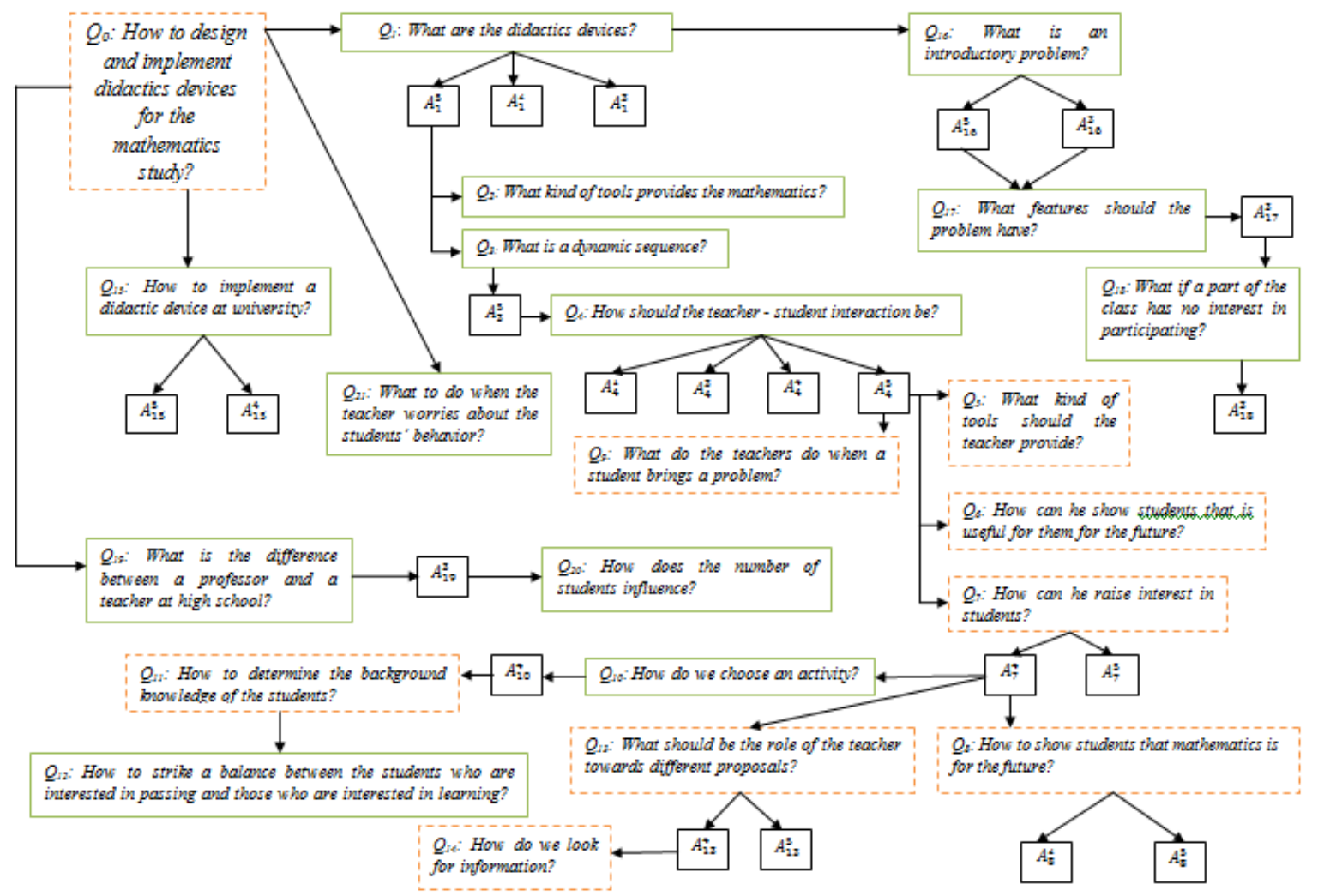

Scheme 1. Set of questions and answers that emerged from the $Q_{0}$ study

Voluntarily, a representative from each group explained their proposal. Firstly, $F T_{1}^{5}$ was commissioned to inform the study community the questions and answer raised in Group 5 . The first issue that they were made: $Q_{1}$ : What are the didactics devices? This question was a problem for FT. This sensation was recorded in the on-line class journal.

The answer $\left(A_{1}^{5}\right)$ that Group 5 provided is id below:

- A la hora de enseñar tanto al alumno que tiene interés en aprender cómo al alumno pue sólo guiere aprobar. la propuestá sería diseñar una secuencia dinámica donde participen interactuán do tanto alumnos como profesor y no sea sólo el profesor el " "PROTAgOnista". 
[At the moment of teaching not only the students who have interest in learning but also the students who only want to pass, the proposal would be to design a dynamic sequence in which they take part interacting both students and teacher and in which just the teacher is the "protagonist".]

Figure 1. Answer to $Q_{1}$ provided by Group 5

The indicated response does not answer to $Q_{1}$ directly, nevertheless we observe the concern of the Group 5 for preparing didactic devices involving the students who demonstrate interest in learning as well as those that do not have it. Here the proposal is orientated towards how to organize the education, where the teacher does not turn out to be the protagonist of the study process. Next, the response was enriched by the following response:

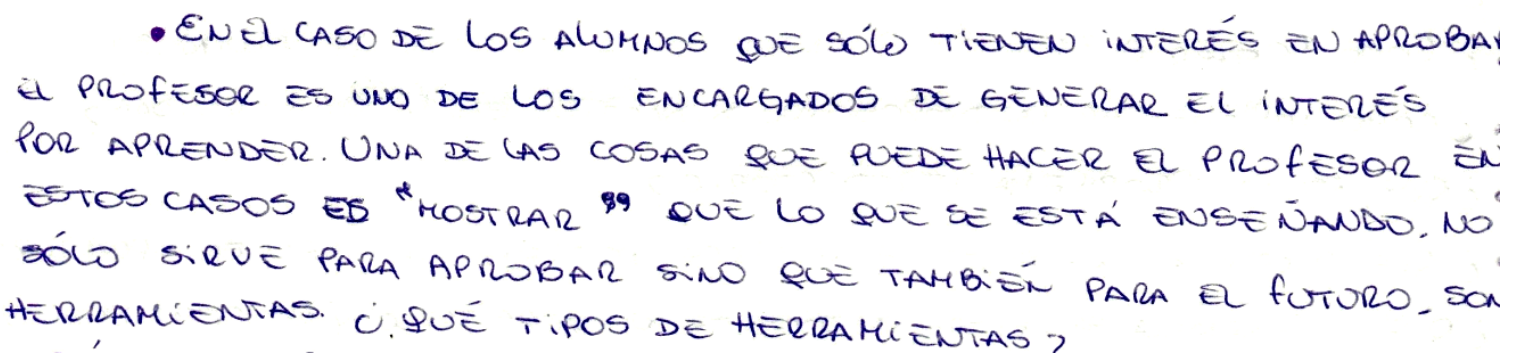

[For students who only have interest in passing the teacher is responsible for generating interest in learning. One of the things that the teachers can do in these cases into "show" that what is being taught is not only useful for passing but also for the future; they are tools What kind of tools?]

Figure 2. Answer to $Q_{1}$ provided by Group 5

Here, the student assignee to teacher the function of generate interest in learning. However the FT no answers to how the teacher should manage such interest. As stated by the FT response would show the usefulness of knowledge in study. This is an embryo answer that adds meaning to the problem of how to spread mathematical knowledge. Finally, reflection on Group 5 concludes questioning: $Q_{2}$ : What kind of tools provides the mathematics? This is a question that the study community does not provided answer in the first session of the study program.

Although, during the group discussion no more answers to $Q_{1}$ than the indicated were recorded we found the answers provided by the Group 2 and 3: in students' protocol:

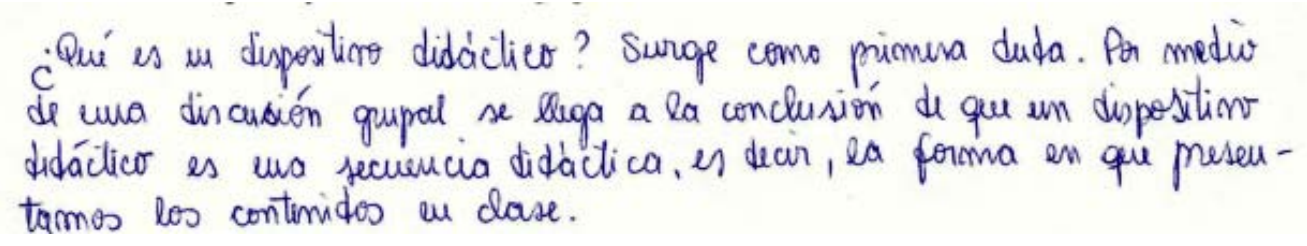

[What is a didactic device? It emerges as the first doubt. Through group discussion it is reached to the conclusion that a didactic device is a didactic sequence, i.e. the way that we present content in class.]

Figure 3. Answer to $Q_{1}$ provided by Group 3

\section{Dispsitivo didactico $\rightarrow$ secuencia de clase. \\ [Didactic device $\rightarrow$ class sequence]}

Figure 4. Answer to $Q_{1}$ provided by Group 2

In particular, in three of the five groups emerged the need to define what a dispositive device is and to set its features, as if it was unique and generally to any situation. This definition was provided from the FT's available knowledge. Though, the students had access to Internet and personal computers, 
we did not notice attempts to look for the definition of different didactic devices, and even less the ones proposed for the Mathematics study. The etymological roots of the word device show various entries found (Souto et al. 1999). In particular, the philosopher Michel Foucault views the devices as a heterogeneous set of elements: speeches, architectural installations, regulations and institutions through which it is possible to describe the relations of power and knowledge (Palacio, 1998). These ideas had been desirable to discuss in the study community, especially linked to the study of the mathematics. Likewise, the RT did not emphasize the need to continue investigating on the mentioned notion. This leads us to rethink the formulation of $Q_{0}$ and its management by RT in the future implementations of the study program.

Next, during the grupal discussion $F T_{2}^{5}$ indicated a new question: $Q_{3}$ : What is a dynamic sequence? The future teacher concluded that a sequence is dynamic ... when the teacher and the student interact and the teacher is not the protagonist $\left(A_{3}^{5}\right)$. From this response emerged question $Q_{4}$ : How should the teacher student interaction be? As the latter question turned out to be of interest in the whole study community, the RT investigated it getting as response that the participation between student and teacher must be active $\left(A_{4}^{5}\right) . F T_{3}^{5}$ defined e active participation as follows (...) in the case of students who are interested in passing, the teacher is one of the persons in charge of raising interest in learning. One of the things the teacher can do in these cases is to "show" that what is being taught is not only useful to pass but also for the future, that would be, what kinds of tools? This response gets back part of the answer provided to $Q_{1}\left(A_{1}^{5}\right)$.

In response to $Q_{4}$, in protocols of 3 groups we find the following answers:

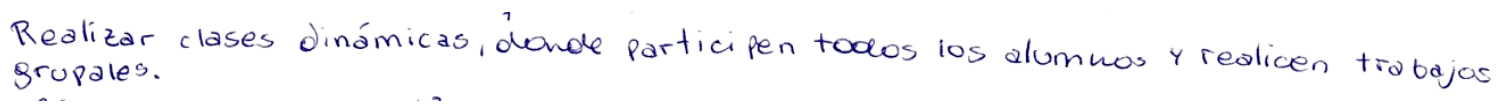

[Give dynamic classes where all the students participate and do group work.]

Figure 5. Answer $\left(A_{4}^{4}\right)$ to $Q_{4}$ provided by Group 4

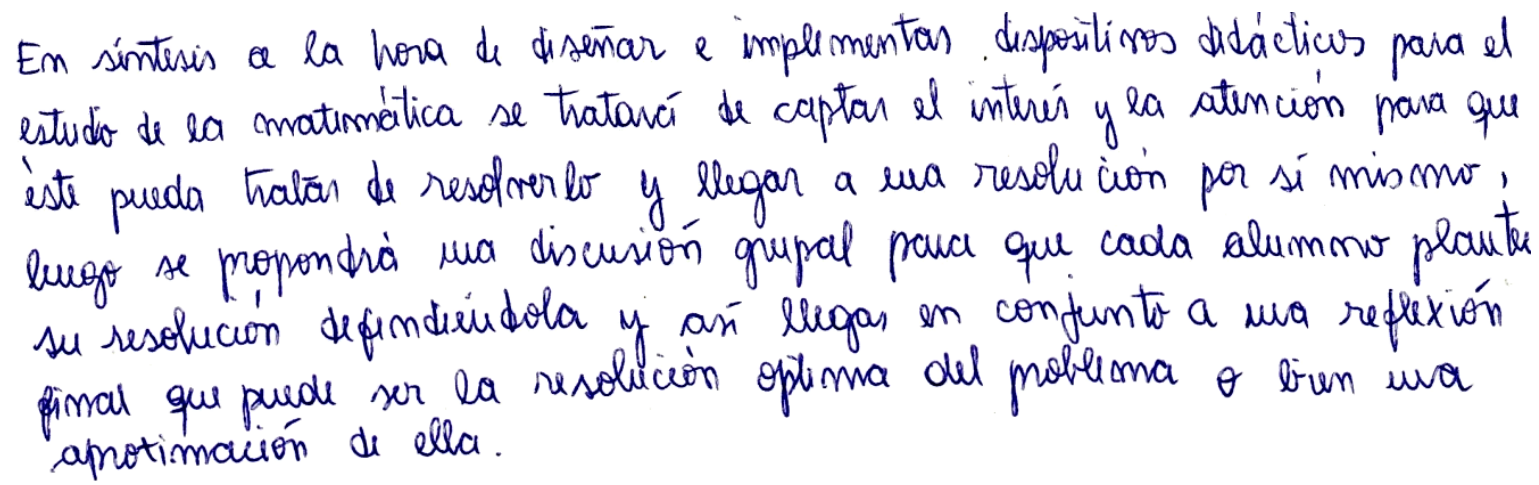

[Summing up, when it comes to design and implement didactics devices to mathematics study. It is intended to capture the interest and attention so that it can be solved and reach to a resolution by itself, then a group discussion will be proposed so that each student shares its resolution defining it and together reach to a final thought that may be the optimal resolution of the problem or an approximation of it.]

Figure 6. Answer ${ }^{\left(A_{3}^{4}\right)}$ to $Q_{4}$ provided by Group 3

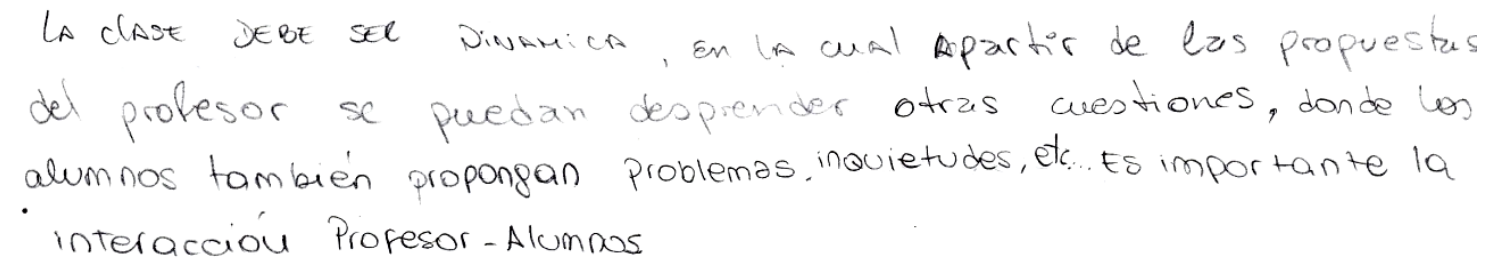


[The class must be dynamic, in which from the teacher's proposals other questions can be deduced, where the students also propose problems, worries, etc. students interaction is important.]

Figure 7. Answer $\left(A_{1}^{4}\right)$ to $Q_{4}$ provided by Group 1

From these protocols it is collected the idea that the teacher's role is to design tasks and students have to respond to them. Likewise, for the FT it is vital that in the study process students get involved and that their activity is not reduced to reproduce what the teacher says and does.

Coming back to the response given by the Group 5, the RT makes the questions $Q_{5}$ : What kind of tools should the teacher provide? $Q_{6}$ : How can he show students that is useful for them for the future? Q7: How can he raise interest in students? To this last question $F T_{1}^{5}$ indicated: connect everything to real life $\left(A_{7}^{5}\right)$. The RT asked FT to indicate what they understand by connecting everything to daily life. This generated several responses such as: $F T_{2}^{4}$ : Situations where you know they can live in $\left(A_{7}^{4}\right)$. Then the RT asked $Q_{8}$ : How to show students that mathematics is for the future? How ask $F T_{1}^{2}$ signaled: Yes, mathematics, has a usefulness but I do not know if for the future $\left(A_{9}^{2}\right)$. In the same direction $F T_{1}^{5}$ indicated: I would not generalize in saying that all contents will, say, be useful for everyday life $\left(A_{8}^{5}\right)$.

Then the discussion went around the issue resumed by $F T_{2}^{5}$ : $Q_{4}$ : How should the teacher - student interaction be? Here students sought to respond, leading the discussion to establishing what kinds of problems students should solve. Thus $F T_{3}^{5}$ indicated: The problems that the teacher will bring have to have his correspondence with the reality. To this $F T_{1}^{5}$ added: (...) That makes sense. Then, $F T_{3}^{5}$ indicating continued response $Q_{4}$ :

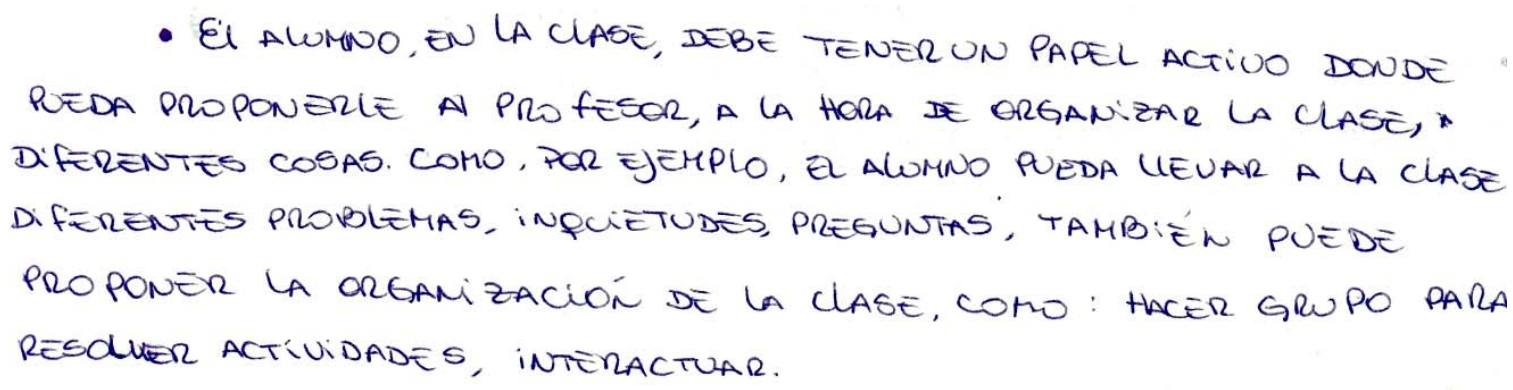

[The students, in the class, must have an r activate role in which they could propose to the teacher, at the moment of organizing the class, different things like, for example, that the students could take to the class different problems, worries, questions, also they can propose the class organization, since: to form groups to solve activities, to interact.]

\section{Figure 8. Answer $\left(A_{4}^{5}\right)$ to $Q_{4}$ provided by Group 1}

This answer led to the RT recovers the question that the FT were responding ... then we should also have to solve the problem of what do the teachers do when a student brings a problem? [Q9].

Here the discussions turned around the fact whether the teacher knows or not the answer to the problem as well as whether the problem makes the students turn aside of the way proposed by the teacher. Particularly, in this discussion there were not consensuses that allow to outline a response to Q.

Next the members of Group 4 provided their proposals, adding everything that was not mentioned by Group 5. Thus $F T_{1}^{4}$ recovered the question $Q_{7}$ : How can interest in students be raised? $F T_{1}^{4}$ contributed the answer $A_{7}^{4}$ : Suggesting dynamic classes, where students participate and work in groups ... then we said, How do we choose an activity? $\left(Q_{10}\right)$. The need to respond immediately is imperative in the students' group, indicating the following answer $\left(A_{10}^{4}\right)$ : 
- El proresor debe pensar wáles son los conocimientos previos y herramientas que
los alummos tienen. para peder abordar un nuevo conocimiento.

[The teacher duties think which are the previous know and tools that have the students. To can address a new know.]

Figure 9. Answer $\boldsymbol{A}_{10}^{4}$ to $Q_{10}$ provided by Group 4

In relation to the indicated answer, the RT questioned: $Q_{11}$ : How to determine the background knowledge of the students? The discussion continued where Group 4 members questioned $Q_{12}$ :

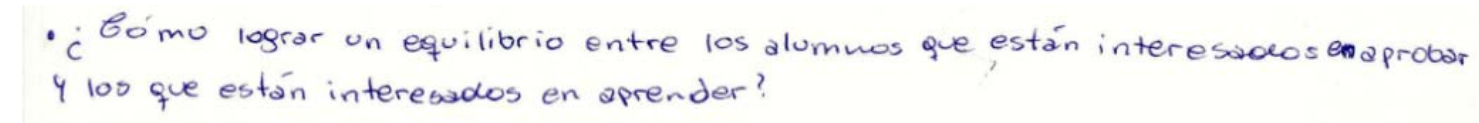

[How to strike a balance between the students who are interested in passing and those who are interested in learning?]

Figure 10. Question $Q_{12}$ provided by Group 4

Then $F T_{1}^{4}$ reopened the question $Q_{7}$ : How can we raise interest in students? The group provided the answer $A_{7}^{4}$ : ... we said, proposing everyday problems as they had said, games, or that students come with their own concerns and propose different activities. To this $F T_{2}^{4}$ added: That it is not only the teacher. In response, the RT settled the question $Q_{13}$ : What should be the role of the teacher towards different proposals? Thus, $F T_{1}^{5}$ provided the following answer: $A_{13}^{5}$ :... have to see that ... how the various concerns of students fit, also with the content that are giving ... Nor say this because it is a bit frustrating, perhaps, for kids who are showing an interest ... maybe at that moment they lack the tools and they may need to deal with it later because it lacks tools and you give them the solution to the problem I do not know if makes sense for the student that you give him the solution. We infer that for these FT the students have to know all the contents to improve in the study. Here are noticed two key aspects that characterize the traditional teaching, and are rooted in the FT: on the one hand is the teacher who decides on the means of study, even though the students propose to solve a problem. The teacher is who controls the dialectic of light boxes and black boxes. It is him who decides in which what grey level praxeologies are studied. On the other hand, for the FT it is necessary to know everything about a notion to be studied. This is directly opposed to the exoteric and procognitiva attitudes. There is not provisional acceptance of knowledge which through studying it is about to be conquered.

On the other hand, $F T_{1}^{4}$ brought a response $\left(A_{13}^{4}\right)$ to $Q_{13}$ in which a greater allocation of autonomy for the study is noticed in the students: Seeing which ones relate more to the content you are working with and tackle directly, and write down all the concerns and later work them out. With them or that they alone investigate and look for some answers. This proves to be a consistent response to pedagogy research and is in correspondence with the study and research dialectic. Here it would have been necessary to continue working on what they understand by investigate and seek and how to manage this activity in the math class at different educational systems.

On the other hand, $F T_{1}^{5}$ indicated: If the student have the tools at that moment, it is good that they try it themselves, so they see that they can. This $F_{2}^{4}$ added: we put that when we suggested that the student cannot resolve the problem proposed by the teacher, so then they are encouraged to look for information... In this instance, the RT placed the following question: $Q_{14}$ : How do we look for information? To this question the study community gave no answer.

Then, Group 4 finalized its proposal laying out the next question: $Q_{15}$ : How to implement a didactic device at university? To this question the community study concluded that all these previous questions must also be brought up to this education level. 
Next, the Group 3 indicated that to the initial question $Q_{1}$ : What are the didactics devices?, the question $Q_{16}$ was derived: What is an introductory problem? This question was conceived considering a teaching based on the Didactic Situations Theory, since it constitutes one of the closest praxeological equipment studied by FT. To this question the group members provided the answer $\left(A_{16}^{3}\right)$ that we indicate next:

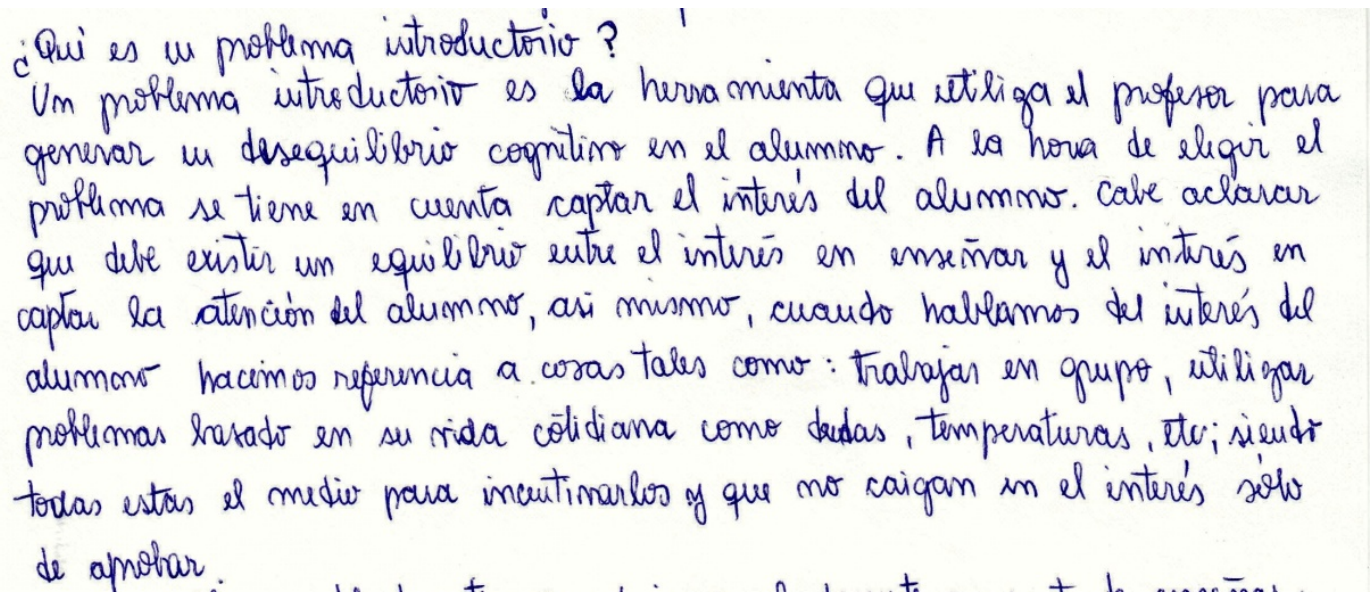

[What is an introductory problem? An introductory problem is the tool used by the teacher to generate a cognitive imbalance in the student. When choosing the problem, capturing the student interest is taken into account. It should be pointed out that there must be a balance between the interest in teaching and the interest in capturing the students' attention, and when we talk about the students' interest we refer to things such as: group work, using problems based on their daily lives as doubts, temperatures, etc., all of these are means to encourage them and keep them away from just passing the course.]

Figure 11. Answer $\left(A_{16}^{3}\right)$ to $Q_{16}$ provided by Group 3

In this response again is seen the responsibility assigned to the teacher to generate interest in students (although they do not have it). This is reaffirmed by $F T_{1}^{5}, A_{16}^{5}$ : Basically what we did was to address the question of what conditions must have the problem that we propose to capture the attention of students.

Then, the discussion turned to questioning about the type of problems that teachers should propose. $F T_{3}^{3}$ indicated: $Q_{17}$ : What features should the problem have? On the other hand, $F T_{1}^{3}$ went deeper into the teacher's role indicating: $A_{17}^{3}$ : There must be a balance between what the teacher proposes ... it can fall into what the animator is, who just wants to capture the attention of students... To which $F T_{3}^{3}$ added: Not just be an entertainer but also present the content ... and $F T_{2}^{3}$ indicated: That's when we say there must be a balance between the interest in teaching and the concern to capture the student's attention.

Then, the $F T_{1}^{3}$ resumed what they conceive as one of the teacher main functions which is to manage the students' interest in learning: $Q_{18}$ : What if a part of the class has no interest in participating? So, the group provided a new answer $A_{18}^{3}$ : ...We put that it could be proposed an additional activity that complements with the previous one, for whom generates interest and... students interact among them, and with the teacher. Again the need for the allocation of the teacher who should be the manager of the interest in learning in students emerges. This responsibility that students learn or not is assigned to the teacher, beyond employing didactic praxeology, if students refuse to learn, the learning process will not be possible.

Finally, the contributions of Group 3 were placed in questions related to teaching at the University $F T_{3}^{3}$ $Q_{19}$ : What is the difference between a professor and a teacher at high school? Thus, members of 3 Group 3 raised the following answer: $A_{19}^{3}$ : ... University professor wants more to give the content, related to the number of students in the class. To this $F T_{2}^{4}$ indicated: I put a second question that is how does the number of students influence? $\left(Q_{20}\right)$. 
Then, Group 2 members indicated $F T_{1}^{2}$ : ...What to do when the teacher worries about the students' behavior? $\left(Q_{21}\right)$ To this question the community study provided no response.

Group 1 members indicated that their questions are reflected in the ones expressed by other groups and that their concern was responding more than asking.

Finally, the set of questions posed in this first session was the primary means from which the study community began. In subsequent classes, each small working group reviewed and modified the means of study according to their needs The RT provided reading material following curriculum guidelines (Chevallard, 1999; 2007; 2012; Bosch \& Gascón, 2010; Otero, Fanaro \& Llanos, 2013). Thus, the course curriculum requires the ATD study, which causes that what is conceived as SRP, may be interfered with its natural course by the restrictions imposed by the institution. This activity led to changes in the original study middle and new questions and answers that emerged from the ATD study.

From the analysis of the questions and answers pairs that emerged from the study community, we formulate categories inductively (Mejía, 2011), which allow to synthesize and characterize the primary study medium. The categories and subcategories are described below:

Questions type. This refers to the style of questions proposed by the study community. We distinguish two types of questions:

Interrogative What. These questions were initially formulated from the interrogative What and are characterized as short-lived life? Since they are formulated in order to give an immediate and finished response.

Interrogative How. These questions were initially formulated from the interrogative How. Such issues go beyond the demands of mere information. They outsource an issue in which their research generates questions and answers.

Types of responses. It Refers to the type of response that brings the study community to the issues raised. We distinguish three kinds of responses:

Questions in weak sense (QWS). These answers provide a closed and completed response and new questions. Are not proposed

Questions in half sense (QHS). These responses are formulated as a finished and closed answer, and also derivate in the formulation of a new question.

Questions in strong sense (QSS). These answers generate several questions that the study community cannot provide an answer, which requires restart their study.

Main actor. This category includes the actor of the study process that makes each question. Each actor is identified as follows:

Futures Teacher (FT)

Research Teacher (RT).

Table 1. Analysis results of the questions and answers pairs formulated by the study community

\begin{tabular}{llll}
\hline Interrogative What... & Interrogative How... & Types of responses & Main actor \\
& $Q_{0}$ & QSS & RT \\
$Q_{1}$ & & QHS & FT \\
$Q_{2}$ & & Unanswered & FT \\
$Q_{3}$ & \multirow{2}{*}{$Q_{4}$} & QWS & FT \\
$Q_{5}$ & & QWS & FT \\
\hline
\end{tabular}




\begin{tabular}{llll}
\hline & $Q_{6}$ & Unanswered & RT \\
& $Q_{7}$ & QSS & RT \\
$Q_{9}$ & $Q_{8}$ & QWS & RT \\
& & Unanswered & RT \\
& $Q_{10}$ & QHS & FT \\
& $Q_{11}$ & QHS & RT \\
& $Q_{12}$ & Unanswered & FT \\
& $Q_{13}$ & QHS & RT \\
& $Q_{14}$ & Unanswered & RT \\
$Q_{16}$ & $Q_{15}$ & QWS & FT \\
$Q_{17}$ & & QWS & FT \\
$Q_{18}$ & & QWS & FT \\
$Q_{19}$ & & QWS & FT \\
& & QWS & FT \\
$Q_{21}$ & & Unanswered & FT \\
\hline
\end{tabular}

On the 1 Table 1 we show the analysis results of the questions and answers pairs formulated by the study community.

From the analysis of the table, we highlight that of the 22 questions, only 2 are formulated in a strong sense. Both were provided by the RT, one of them is the initial generator question $Q_{0}$, and the other is questions $Q_{7}$ that refers to how the teacher manages the students' interest in the mathematics study.

We highlight the RT tendency to propose questions that begin with the interrogative what (8 questions out of 10). While of the 12 questions that begin with interrogative how, only 5 were made by FT. This highlights the need of the FT to formulate questions that can provide immediate and finished answers. On the other hand, we emphasize that 12 questions support answers in weak and half sense. Also, there is a high number of questions $(n=8)$ that the study community did not provide an answer, which makes that the means requires to continue their study in the following sessions.

\section{Final reflections}

Throughout the study program that we designed and implemented, we engage the FT in a type of unusual activity in the teacher training systems. We seek to study functionally the teacher's didactic praxeological equipment, avoiding to be imposed as a requirement of the training system. The study program has the main feature of being a long-term work, with the aim to answer a generating question that constitutes to be raison of the teacher's profession.

The class session described in this work constituted the main basis from which a SRP on the mathematics teaching was developed. Here mathematics FT were plunged to one of the fundamental problems of the teaching profession that is $Q_{0}$ : How to design and implement didactics devices for the mathematics study?

The analysis results of the first session indicate that the study of the generating question by FT is reduced to propose questions, and possible immediate answers, as if there was no more to study. This required that the RT should intervene on several occasions to problematize the questions that FT made. We consider that the questions and answers pairs proposed for the FP do not invite to reflection. The largest proportion of these questions aim at establishing what to do so that the students have interest in the mathematics study.

This interest seems to be linked to what the students like more than what they are interested in the mathematics as a knowledge field. In fact, in the manifestations of the FT the issue on mathematics education is absent. So, his interventions stay at the pedagogic level. This characterization of the teacher's profession does not recognize the aspect relative to the citizens' formation, and emphasizes as the teacher responsibility that the students like the mathematics. 
In the subsequent sessions, we continued studying and modifying the study means conceived in the first session. Here we get greater evidence of the development in the FT attitudes compatible to enter the research and world questions pedagogy. These results will be reported in our future work.

\section{References}

Artaud, M., Cirade, G. \& Jullien, M. (2011). Intégration des PER dans l'equipement praxéologique du professeur. Le cas de la formation initiale. En M. Bosch et. al (Eds.), Un panorama de la TAD (pp. 769-794). Barcelona: Centre de Recerca Matemàtica.

Azcárate, P. (2004). Los procesos de formación: En busca de estrategias y recursos. En E. Castro \& E. de la Torre (Coord). Actas del Octavo Simposio de la Sociedad Española de Investigación en Educación Matemática (pp. 43-60) A Coruña: Universidade da Coruña.

Ball, D., Lubienski, S. \& Mewborn, D. (2001). La investigación sobre la enseñanza de las matemáticas: el problema no resuelto de los conocimientos matemáticos de los docentes. En V. Richardson (Ed.), Manual de investigación sobre la enseñanza (4 a ed.). Nueva York: Macmillan.

Blanco, L. (2004). Problem solving and the inicial and theoretical education of teachers in Spain. Mathematics Teacher Educational and Development, 6, 37-48.

Brousseau, G. (1986). Fondements et méthodes de la didactiques des mathématiques. Recherches en Didactique des mathématiques, $7(2), 33-115$.

Bosch, M. \& Gascón, J. (2009). Aportaciones de la Teoría Antropológica de lo Didáctico a la formación del profesorado de matemáticas de secundaria. En M.J. González, M.T. González \& J. Murillo (Eds.), Investigación en Educación Matemática XIII (pp. 89- 113). Santander: SEIEM.

Chapman, O. (2013). Investigating teachers' knowledge for teaching mathematics. Journal of Mathematics Teacher Education, 16, 237-243.

Chevallard, Y. (1985). La transposition didactique. Grenoble: La Pensée Sauvage.

Chevallard, Y. (1999). L'analyse des pratiques enseignantes en théorie anthropologique du didactique. Recherches en Didactique des Mathématiques, 19/2, 221-266.

Chevallard, Y. (2007). Passé et présent de la théorie anthropologique du didactique. http:/ /yves.chevallard.free.fr, (accessed September 2014)

Chevallard, Y. (2012) Teaching Mathematics in tomorrow's society: a case for an oncoming counter paradigm. 12th International Congress on Mathematical Education. 8-15 July, 2012, Seoul, Korea. http:/ / yves. chevallard. free. fr/, (accessed September 2014).

Chevallard, Y. (2013a). Journal du Seminaire TAD/IDD. Théorie Anthropologique du Didactique \& Ingénierie Didactique du Développement. http://yves. chevallard. free. fr/spip/spip/IMG/pdf/journal-tad-idd-2012-2013-5.pdf, (accessed September 2014).

Chevallard, Y (2013b). Éléments de didactique du développement durable. Leçon 3. http:/ / yves. chevallard. free. $\mathrm{fr}$ /spip/spip/IMG/pdf/Didactiquedu-DD-2012-2013-3.pdf, (accessed September 2014).

Corica, A. \& Otero, M. (2013). The Mathematics Teacher Formation and the Teaching for Research and Study Course. Journal of Arts $\mathcal{E}$ Humanities, 2 (7), 23 -36.

Corica, A. \& Otero, M. (2014). La formación de profesores de Matemática desde la Teoría Antropológica de lo Didáctico: un estudio de caso. Perspectiva Educacional. 53(2), 20 - 44.

Corral, C. \& Zurbano, E. (2000). Propuestas metodológicas y de evaluación en la formación inicial de los profesores del área de didáctica de la matemática. Servicio de publicaciones de la Universidad de Oviedo: Oviedo.

Douady, R. (1984). Relación enseñanza-aprendizaje, Dialéctica Instrumento Objeto, Juego de marcos. Revista de Didáctica, 3, 1 10.

Font, V. (2011). Competencias profesionales en la formación inicial de profesores de matemáticas de secundaria. UNION, 26, 925.

Font, V., Rubio, N., Giménez, J. \& Planas, N. (2009). Competencias Profesionales en el Máster de Profesorado de Secundaria. UNO, 51, 9-18

García, M. (2001). La formación inicial de profesores de matemáticas. Fundamentos para la definición de un currículum. En D. Fiorentini (Ed.). A formaçao de profesores de matemática. Estudos e contribuiçoes teorico-metodologicas de Brasil Espanha e Portugal. Brasil: UNICAMP.

Gascón, J. (2003). La pedagogía y la didáctica frente a la problemática del profesorado de Matemáticas. Comunicación presentada en el XVI Congreso de enciga, Cangas de Morrazo, Pontevedra.

Godino, J. (2009). Categorías de Análisis de los Conocimientos del Profesor de Matemáticas. UNION, 20, $13,31$.

Koc, Y., Peker, D. \& Osmanoglu, A. (2009). Supporting teacher professional development through online video case study discussions: An assemblage of preservice and inservice teachers and the case teacher. Teaching and Teacher Eduaction, 25(8), 1158 - 1168.

Hernández, R., Fernández, C. \& Baptista, M. (2010). Metodología de la investigación. México D. F.: Mc Graw Hill.

Hill, H., Ball, D. \& Schilling, S. (2008). Desembalaje del contenido pedagógico del conocimiento: Conceptualización y medición relacionados con el tema del conocimiento de los profesores a los estudiantes. Diario de Investigación en Matemáticas Educación, 39, 372-400.

Hill, H., Schilling, S. \& Ball, D. (2004). El desarrollo de las medidas de los docentes conocimiento de las matemáticas para la enseñanza. Revista de la Escuela Primaria, 105, 11-30.

Ladage, C. \& Chevallard, Y. (2010). La pédagogie de l'enquête dans l'éducation au développement durable. http:/ / yves.chevallard.free.fr/, (accessed September 2014).

Mejía, J. (2011). Problemas centrales del análisis de datos cualitativos. Revista Latinoamericana de Metodología de la Investigación Social, 1(1). 47 - 60 . 
Marietti, J. (2010). Questionnement du monde et pédagogie de l'enquête: obstacles et points d'appui. (Mémoire de 2e année de master recherche de sciences de l'éducation, Université de Provence). http://yves.chevallard.free.fr/, (accessed September 2014)

Otero, M., Fanaro, M., Corica, A., Llanos, V., Sureda, P. \& Parra, V. (2013). La Teoría Antropológica de lo Didáctico en el aula de Matemática. Tandil: Dunken.

Otero, M., Fanaro, M. \& Llanos, V. (2013). La Pedagogía de la Investigación y del Cuestionamiento del Mundo y el Inquiry: un análisis desde la enseñanza de la Matemática y la Física. REIEC, 8 (1), 77 - 89.

Parra, V., Otero, M. \& Fanaro, M. (2013a). Recorridos de Estudio e Investigación co-disciplinares a la Microeconomía. NÚMEROS, 81, 17 - 35

Parra, V., Otero, M. \& Fanaro, M. (2013b). Los Recorridos de Estudio e Investigación en la Escuela Secundaria: resultados de una implementación. BOLEMA, 27, 847 - 874

Palacio, L. (1998). Reflexiones sobre el texto escolar como dispositivo. Revista Educación y Pedagogía, X(21), 217- 236.

Parada, S. \& Pluvinage, F. (2014). Reflexiones de profesores de matemáticas sobre aspectos relacionados con su pensamiento didáctico. RELIME, 17 (1), 83 - 113

Polo, I., González, M., Gómez, P. \& Restrepo, A. (2011). Argumentos que utilizan los futuros profesores cuando seleccionan tareas matemáticas. En M. Marín, G. Fernández, L. Blanco \& M. Palarea (Eds.), Investigación en Educación Matemática XV (pp. 491-502). Ciudad Real: Sociedad Española de Investigación en Educación Matemática.

Rico, L. (2004). Reflexiones sobre la formación inicial del profesor de matemáticas de secundaria. Revista de currículo y formación de profesorado, 8(1), 1-15.

Robert, A. \& Pouyanne, N. (2005). Formar formadores de maestros de matemáticas de educación media: ¿Por qué y cómo?. Educación Matemática, 17(2), 35-58.

Ruiz, A., \& Sierra, T. (2011). La formación matemático-didáctica del profesorado de secundaria. En M. Bosch et. al (Eds.), Un panorama de la TAD (pp. 769-794). Barcelona: Centre de Recerca Matemàtica.

Rubio, N., Font, V., Giménez, J. \& Malaspina, U. (2011). Pre-service teachers learning to assess mathematical competencies. A: T. Rowland et al. (Eds.). Proceedings of the VII Congress of the European Society for Research in Mathematics Education. Rzsézow, Polònia.

Sanchez, V. (2003). An approach to collaboration in elementary pre-service Teacher Education (pp. 57-68). En A. Peter-Koop, V. Santos-Wagner, Ch. Breen \& A. Begg (eds.) Collaboration in Teacher Education. Examples from the Context of Mathematics Education. Kluwer Academic Publishers.

Sanchez, V. \& García, M. (2004). Formadores de profesores de Matemáticas. Una aproximación teórica a su conocimiento profesional. Revista de Educación, 333, 481-493.

Sierra, T., Bosch, M., \& Gascón, J. (2012). La formación matemático - didáctica del maestro de Educación Infantil: el caso de “cómo enseñar a contar". Revista de Educación, 357, 231 - 256.

Silverman, J., \& Thompson, P. (2008). Toward a framework for the development of mathematical knowledge for teaching. Journal of Mathematics Teacher Education, 11, 499-511.

Souto, M., Barbier, J., Cattaneo, M., Coronel, M., Gaidulewicz, L., Goggi, N. \& Mazza, D. (1999). Grupos y dispositivos de formación. Buenos Aires: Novedades Educativas.

Sowder, J. (2007) La enseñanza de las matemáticas y el desarrollo de los maestros. En F.K. Lester (ed.). Segundo Manual de Investigación en Didáctica de la Matemática y de aprendizaje (Págs. 157 a 223). Charlotte, Carolina del Norte: Consejo Nacional de Profesores de Matemáticas

Steff, L. \& Thompson, P. (2000). Teaching experiment methodology: underlying principles and essential elements. In A. Nelly \& R. Lesh (Eds.). Handbook of research design in mathematics and science education (pp. 267-306). Mahwah: NJ Lawrence Erlbaum Associates.

Towers, J. \& Rapke, T. (2011). Preservice Teachers' Learning from an Online, Video-based, Mathematics Professional Development Resource. International Electronic Journal of Mathematics Education, 6(1), 5-26.

Wood, T. (2008). El manual internacional de la formación del profesorado de matemáticas. Rotterdam: Sense Publishers. 